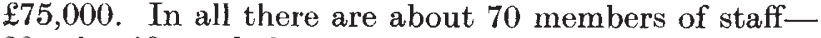
20 scientific and the rest technical staff. The building has ground floor laboratories for biochemistry, tissue culture and electron microscopy; the first floor consists of animal rooms for the maintenance of rats, rabbits and guinea-pigs, and includes special rooms for surgery and the isolation of experimental animals given high levels of radioactive isotopes. Another feature of this floor is the facility for breeding specific pathogen-free rats on a relatively small scale.

Research at present includes studies on the effect of ascorbic acid on collagen and elastin biosynthesis, the nutrition of fibroblasts in culture, the chemistry and metabolism of the bound form of nicotinic acid in cereal grains, and electron microscopy of chromosomes. The role of bactoprenol in bacterial membranes is also being investigated.

One particularly interesting topic of research, in its very early stages, is an investigation of the diet of the Hazda tribe. This very primitive tribe of northern Tanzania is reported to eat meat only once in about 3 weeks and yet the members are, by tropical standards, very healthy. (Forty members from two tribes have, however, been known to virtually strip the meat off an elephant in a few days.) The remainder of the time, they feed on nuts and berries including mahlaloka and lashana. Dr Southgate is now analysing the food as part of a joint project with Dr J. M. Woodburn of London University to see how the tribe flourishes on such a meagre diet. Such an investigation may give an idea of the diet and nutrition of man at an early stage of civilization, thereby throwing light on at least one of the factors which has influenced the development of human nutritional patterns and requirements.

\section{Medical Priorities}

The late Sir Ernest Rock Carling was for many years a governing trustee of the Nuffield Provincial Hospitals Trust and chairman of the trust's medical advisory committee. As an annual memorial to him, the Rock Carling Fellowship was founded - each holder having the task of reviewing in a monograph the state of knowledge and activity in one of the fields in which Sir Ernest was particularly interested. Professor W. J. H. Butterfield of Guy's Hospital and Medical School, who is the most recent holder of the fellowship, has called his monograph Priorities in Medicine.

Although in the final chapter Professor Butterfield sets out ten selected priorities, some of these seem to be more heavily stressed than others in the text. As he points out, the priorities are based on personal experiences and refer particularly to the situation in London. Not surprisingly, some of the issues raised were also considered by the Royal Commission on Medical Education. Had the monograph been written after the report of the Royal Commission was published, it might have turned out differently, but many of Professor Butterfield's suggestions are still stimulating and will provide food for further thought.

One noed clearly expressed is the need for better health education. This stems from the fact that acute diseases have to a large extent given way to chronic ones, which the public tend either to ignore or to try and treat themselves. Although health education has made some progress, Professor Butterfield suggests that the chemist's shop would be a good place to advance it further, and that experts must be willing to provide basic data for the production of films and film strips for schools. Another priority which Professor Butterfield appears to support wholeheartedly is screening as a means of tracing unrecognized disease. Indeed, in the field of cervical cytology, sereening-as Professor Butterfield points out-has already started. He anticipates, however, that one major drawback to selective screening for chronic illness is the fact that the framework of the National Health Service as organized at present is not really suitable; in part because access

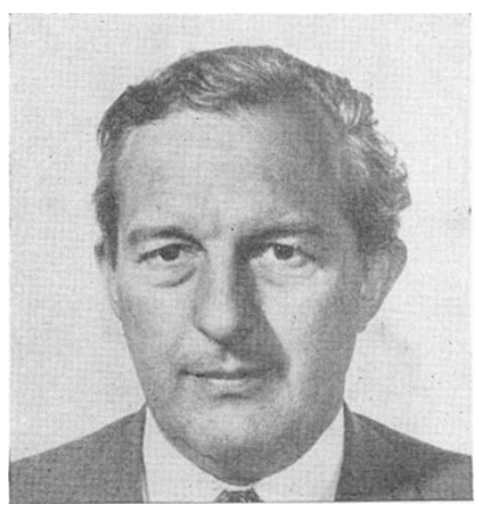

Professor W. J. H. Butterfield.

is not available to the population at risk, and in part because of the problem of people moving from place to place.

Research is also considered a priority; the National Health Service costing more than $£ 1,400$ million a year "must expect to emulate the other successful corpora. tions by investing at least several million pounds per year on research". Better management, too, he suggests, is needed, thereby creating a "loop of ideas"research leading to better understanding, leading to better management, and so to better care and better morale. The long term target must be "an unattainable but generally desirable medical Utopia".

The possibilities for community (general) practice receive particular attention, Professor Butterfield favouring a structure consisting of the concentration of three or four group practices in a main centre where doctors would hold their general consulting sessions seeing patients by appointment. To assist the main centre would be satellite units where other activities not requiring diagnostic or other equipment and welfare could be carried out and supervised by the practitioner. Each of the group practices would be responsible for all aspects of medical care in its particular sector of the town. The new town of Thamesmead has provided a suitable site for such a plan, and here a Joint Health Services Advisory Committee has been set up, probably the first of its kind in the country. By recruiting young medical assistants to work in such communal practices, Professor Butterfield hopes that the flow of emigrants could be reduced.

On a more speculative level, he suggests that in view of the fact that large capital investments will be involved in the Thamesmead project and others like it, it might be more efficient to "sequestrate funds" from the various branches of the National Health Service and put them under the control of a local or area health board. 